This phenomenon may also play a role in the system studied by Mackay's group. Recently, breakdown of classical transport relations has also been observed in colloidal suspensions with particles larger than $100 \mathrm{~nm}$, much larger than the polymers in the surrounding matrix, and it is thought to be due to matrix inhomogeneities ${ }^{10}$.

These studies demonstrate the interesting phenomena that can arise at the nanoscale as a result of the confluence of molecular and macroscale physics. In the study by Mackay et al., for example, because the nanoparticles and matrix have the same chemical composition, the only difference between them is entropic, arising from the reduced number of conformations available to the crosslinked polymers in the particles, compared with the conformational freedom of the matrix. Moreover, the polymer and particle are roughly the same size. This size similarity is very different from so-called plasticizers - molecules considerably smaller than the polymer molecules, which intersperse within the matrix on molecular scales to lower its $T_{\mathrm{g}}$. At the opposite end of the spectrum are traditional composites and particulate suspensions, in which the particles are large and components mix only on micrometre and larger scales, and where viscosity generally increases on addition of particles. The experimental system of Mackay and co-workers has made it possible to work somewhere in between these two extremes, due to the similar size of particle and polymer.

The work by Mackay and colleagues is but one of many to highlight the fascinating science that can occur in soft materials and complex fluids in the nanometre realm. The new-found ability of scientists and engineers to manipulate matter on the nanoscale also creates opportunities for fabricating structures and novel materials with no counterpart on macroscopic scales. Novel structures are possible because of a delicate interplay between thermodynamic immiscibility, geometric and topological constraints, and highly specific interactions only possible at nanometre scales ${ }^{11}$. In these cases, like in the work of Mackay et al., the ways in which the laws of nature conspire to produce new science and new technological opportunities present exciting challenges to experimentalists and theoreticians alike.

\footnotetext{
References

1. Mackay, M. E. et al. Nature Materials 2, 762-766 (2003).

2. Einstein, A. Ann. D. Phys. Leipzig 19, 371-381 (1906)

3. Starr, F. W., Schroeder, T. B. \& Glotzer, S. C. Phys. Rev. E 64, 021802 (2001).

4. Starr, F. W. et al. Phys. Rev. Lett. 89, 125501 (2002).

5. Jones, R. A. L. Nature Mater. 2, 645-646 (2003).

6. Bennemann, C. et al. Nature 399, 246-249 (1999)

7. Russell, E. V. \& Israeloff, N. E. Nature 408, 695-695 (2000).

8. Deschenes, L. A. \& Vanden Bout, D. A. J. Chem. Phys. 292, 255-258 (2001).

9. Ediger, M. D. Ann. Rev. Phys. Chem. 51, 99-128 (2000).

10. Solomon, M. J. \& Lu, Q. Curr. Opin. Colloid Interface Sci. 6, 430-437 (2001).

11. Zhang, Z. L. et al. Nano Lett. published online 23 September 2003

(doi:10.1021/nl034454g).
}

\title{
MATERIALWITNESS Freedom to build
}

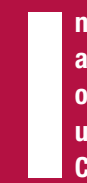

n what style should we build? Now that architecture claims to have broken free of rule books, this question is more urgent than ever. Architects such as Charles Jencks, Frank Gehry and

Daniel Libeskind have found one answer in a startling asymmetry, which Jencks justifies with reference to the physics of phase transitions and symmetry breaking.

It is popular to explain the liberty that architects now enjoy by invoking cultural

trends, particularly the post-modernist determination to avoid prescriptive dogmas. But the dramatic, sometimes unearthly edifices that have appeared in the past decade, such as Gehry's Guggenheim Museum in Bilbao and Libeskind's Jewish Museum in Berlin, are made possible largely by technological advances.

Thanks to these changes, just about anything seems possible. No longer do walls have to be flat, rectilinear or assembled from identical small units. Buildings may have not doors and windows but simply 'orifices'. Rather than being most substantial at their base, towers can balloon outwards as they rise up, like the inverted bell figures of marine tunicates. Such freedom might seem a gift to architects, but it can also be artistically paralysing: invention is rendered motherless.

Computerization of the design and the manufacturing processes has been responsible for much of the expansion in architectural possibilities. But equally significant is the advent of new materials and methods of processing them. Lightweight plastic film can clad buildings in a skin lighter than the air they contain. Self-cleaning glass enables vast or inaccessible areas to be glazed without worrying about maintenance.

Not all of this new architecture is rootless, however.

The plastic domes of the Eden Project, an ecology centre and botanical park in Cornwall, England, throw a nod towards two great pioneers of radical architectural design: Buckminster Fuller and Frei 0 tto. Otto based many of his designs on the shapes of soap films and bubbles, and his tent-like plexiglass roof for the Munich Olympic stadium in 1972 established a curved, airy, 'organic' architectural language that has been reworked on countless occasions - notably in Norman Foster's roof for the Great Court of the British Museum.

Otto's work, and the influence of new materials, lurk in the background of an exhibition entitled Zoomorphic at London's V\&A Museum, which explores the use of animal motifs in architecture. The title is interpreted loosely, encompassing anything from Gehry's explicitly fish-shaped Fishdance restaurant in Kobe, Japan, to buildings based on 'animal architecture' such as nests (a topic explored by ethologist and Nobel laureate Karl von Frisch) or ones that simply display suggestive, 'organic' curves.

One such is the Weald and Downland Museum's Jerwood Gridshell in West Sussex, England. This is basically a wooden barn, acting as a storehouse and conservation workshop. But the undulating body evokes a living form, and its fabric shows the versatility of some traditional materials: the skeleton is a lattice of local oak beams, shaped and moulded while still 'green'. In other words, not all eye-catching new architecture has to be post-modernist or use fancy new materials.

Philip Ball 